\title{
The association of enterotoxigenic and enteropathogenic Escherichia coli and other enteric pathogens with childhood diarrhoea in Yugoslavia
}

\author{
M. ČOBELJIĆ, D. MEL, B. ARSIĆ, LJ. KRSTIĆ \\ Institute of Preventive Medicine, Military Medical Academy, 11000 Belgrade, \\ Yugoslavia \\ B. SOKOLOVSKI, B. NIKOLOVSKI, E. ŠOPOVSKI \\ Institute of Preventive Medicine, 91000 Skopje, Yugoslavia \\ M. KULAUZOV \\ Institute of Public Health, 21000 Novi Sad, Yugoslavia \\ AND S. KALENIĆ \\ Institute of Public Health, 41000 Zagreb, Yugoslavia
}

(Accepted 23 March 1989)

\section{SUMMARY}

The presence of enterotoxigenic and enteropathogenic Escherichia coli (ETEC and EPEC, respectively) was investigated in stool specimens of 1082 preschool children with diarrhoea and in stools of 335 healthy controls in localities in southern Yugoslavia, as well as in 566 children with diarrhoea and in 231 controls living in northern part of the country, during the seasonal peak (AugustNovember) of enteric diseases in 1986.

ETEC were found in $114(10.5 \%)$ children with diarrhoea and in $14(4 \cdot 2 \%)$ controls $(P<0.001)$ in the southern part, and in $26(4.6 \%)$ ill children and one $(0.4 \%)$ well child $(P<0.005)$ in the northern part of Yugoslavia. EPEC were isolated from stools of $85(7.9 \%)$ children with diarrhoea and of $14(4 \cdot 2 \%)$ well children $(P<0.05)$ in localities of southern Yugoslavia, and from $22(3.9 \%)$ ill children and from $10(4 \cdot 3 \%)$ controls in northern Yugoslavia. Nineteen EPEC strains expressed localized adherence to HEp-2 tissue culture cells; all were isolated from stools of ill children.

In southern Yugoslavia, where other enteropathogens were sought, the most commonly found agents in ill children were shigellae (17.5\%), rotavirus $(11.8 \%)$, ETEC, and EPEC. Potential pathogens were detected in $44.5 \%$ cases of sporadic diarrhoea and in $\mathbf{1 5 . 8 \%}$ controls.

This study revealed that ETEC were associated with acute diarrhoeal disease in Yugoslav preschool children. On the other hand, the diagnosis of EPEC-diarrhoea by routine determination of serogroup established the association of these agents with sporadic diarrhoea only in the $0-2$ years age categories in all investigated 
localities. In the less developed southern part of Yugoslavia bacteria were the predominant causative agents of enteric illness during the seasonal peak of this disease.

\section{INTRODUCTION}

It was estimated that about 1000 million cases of acute diarrhoea occurred in 1980 in children under 5 years of age in the developing countries (excluding the People's Republic of China); of these about 5 million died (WHO Geneva, 1983). This disease is also a major cause of morbidity and mortality in infants and young children in all Mediterranean countries (WHO Copenhagen, 1981). Never the less data on the aetiology of gastroenteritis in this area are scarce. Furthermore, the association of enterotoxigenic (ETEC) and enteropathogenic (EPEC) Escherichia coli with this disease has not always been reported (De Mol et al. 1983; Mathewson et al. 1987 ; Spencer et al. 1980).

The primary purpose of this study was to determine the frequency of isolation of ETEC and EPEC from stools of children with and without diarrhoea in an attempt to elucidate their relative importance in the aetiology of acute gastroenteritis in Yugoslav children. In some localities the presence of other enteric pathogens in faecal specimens was also investigated.

\section{MATERIALS AND METHODS}

Patients. This investigation was conducted in four cities and their surroundings in 1986, during the late summer and the beginning of autumn (August-November) when the seasonal peak of enteric diseases usually occurs. The localities of Novi Sad and Zagreb are in the industrialized northern part of Yugoslavia with typical urban populations and the two others (Prilep and Bitolj) are situated in the lessdeveloped southern region where a substantial proportion of inhabitants is involved in agriculture. The patients consisted of infants and preschool children (up to 6 years of age) who attended outpatient clinics acting as primary care centres and in whom the diagnosis 'acute gastroenteritis' was established after physical examination, and in whom there was a history of frequent loose stools in the preceding 1-4 days. Controls were newborn babies and infants visiting 'wellbaby' clinics and children in day-care centres who had neither been ill nor received antibiotics in the 2 weeks before specimen collection.

In all localities stools from ill and well children were screened for ETEC and EPEC. In the localities of Prilep and Bitolj other enteropathogens were also sought.

Methods. Faecal specimens from ill children were obtained as soon as possible after the diagnosis had been established; from healthy controls samples were collected by daily visits to 'well-baby' clinies and day-care centres. From each child only one faecal sample was obtained and processed within $4-6 \mathrm{~h}$. For viral studies a part of the specimen was stored at $-20{ }^{\circ} \mathrm{C}$.

All specimens were inoculated onto Salmonella-Shigella (SS) and MacConkey agar plates and in Selenite $\mathrm{F}$ broth. After incubation, 5-10 E. coli-like colonies from MacConkey agar were pooled in nutrient agar deep for storage and transfer to the Institute of Preventive Medicine, Military Medical Academy, Belgrade for 
testing for enterotoxin production and serogroup. Tests were carried out within 4 months of collection. Each pool was tested for in vitro production of heat-labile enterotoxin (LT) by the CHO-K1 and Vero cell culture assays (Guerrant et al. 1974; Konowalchuk, Speirs \& Stavric, 1977), and for production of heat-stable enterotoxin (ST) by the infant mouse assay (Dean et al. 1972). If the LT or ST activity was registered in a pool an attempt was made to isolate toxin-producing strain(s). The presence of ETEC in a stool specimen was not accepted unless a single colony isolate was obtained. The expression of mannose-resistant hemagglutination (MRHA) of human and bovine erythrocytes by ETEC was tested by the method of Evans et al. (1979). Five $E$. coli colonies from each pool were tested for agglutination with poly- and monovalent antisera (Institute of Immunology, Zagreb) as recommended by Edwards \& Ewing (1972). Strains which did not produce LT or ST and which belonged to the following serogroups were considered as classical EPEC: O 18, O 44, O 55, O 86, O 111, O 112, O 114, O 119, O 125, O 126, O 127, O 128, and O 142 (Levine, 1987). Isolated EPEC strains were tested for mannose-resistant HEp-2 cell adherence by the method of Nataro et al. $(1985 a)$. The identity of all isolated ETEC and EPEC was confirmed by standard biochemical methods (Edwards \& Ewing, 1972).

Other intestinal pathogens were detected and identified using standard methods (Edwards \& Ewing, 1972).

Rotavirus and virus-like particles (VLP) in stool specimens were detected by electron microscopy: 10-20\% faecal suspensions were prepared in PBS; after centrifugation at $2500 \mathrm{rpm}$ for $30 \mathrm{~min}$ supernatants were placed onto formvarcoated grids and stained with $2 \%$ phosphotungstic acid. Each grid was examined on a Philips 201C electron microscope (magnification 30000).

For statistical analyses the $\chi^{2}$ test was used.

\section{RESULTS}

Stool specimens from 1082 ill children and from 335 healthy controls in southern Yugoslavia were examined for ETEC, EPEC, and other enteropathogens. Of these 960 and 239 specimens from ill and well children respectively were also studied for viruses. In northern Yugoslavia, 566 children with diarrhoeal disease and 231 children without diarrhoea were investigated only for the presence of ETEC and EPEC in their stools.

In southern Yugoslavia potential pathogens were detected in 481 (44.5\%) children with diarrhoea and in $53(\mathbf{1 5 \cdot 8} \%)$ healthy controls (Table 1). All were detected in a significantly higher percentage of children with diarrhoea than of controls.

In the northern part of Yugoslavia ETEC were also significantly more commonly recovered in ill children, although the percentage of isolation was lower than in southern Yugoslavia. The rates of EPEC isolation were similar in children with and without diarrhoea.

The age distribution of children infected with ETEC, EPEC, and other pathogens is shown in Table 2. The isolation rates of ETEC were slightly higher in children with diarrhoea aged 2-4 years in southern part, and in 0-2 years age group in northern Yugoslavia. EPEC were more frequently isolated in ill children 
Table 1. Findings of enteropathogens in children with diarrhoea and in healthy controls in Yugoslavia (August-November 1986)

No. $(\%)$ with indicated microorganism

\begin{tabular}{|c|c|c|}
\hline & \multicolumn{2}{|c|}{ No. $(\%)$ with indicated microorganism } \\
\hline & Diarrhoeal group & Control group \\
\hline & \multicolumn{2}{|c|}{ Southern Yugoslavia* } \\
\hline & $(1082 / 960)$ & $(335 / 239) \dagger$ \\
\hline Shigella spp. & $189(17 \cdot 5)$ & $6(1 \cdot 8) \|$ \\
\hline Rotavirus & $113(11 \cdot 8)$ & $12(5 \cdot 0) \S$ \\
\hline Enterotoxigenic $E$. coli & $114(10 \cdot 5)$ & $14(4 \cdot 2) \|$ \\
\hline Enteropathogenic $E$. coli & $85 \quad(7.9)$ & $14(4 \cdot 2) \neq$ \\
\hline Virus-like particles & $25 \quad(2 \cdot 6)$ & $7(2 \cdot 9)$ \\
\hline Salmonella spp. & $11(1 \cdot 0)$ & $1(0 \cdot 3)$ \\
\hline Campylobacter jejuni & $3(0 \cdot 3)$ & 0 \\
\hline Yersinia enterocolitica & $2(0 \cdot 2)$ & $1(0 \cdot 3)$ \\
\hline \multirow[t]{3}{*}{ Mixed infections } & $60 \quad(5 \cdot 5)$ & $2(0 \cdot 6) \|$ \\
\hline & \multicolumn{2}{|c|}{ Northern Yugoslavia } \\
\hline & $(566)$ & $(231) \dagger$ \\
\hline Enterotoxigenic $E$. coli & $26(4 \cdot 6)$ & $1(0 \cdot 4) \S$ \\
\hline Enteropathogenic $E$. coli & $22 \quad(3 \cdot 9)$ & $10(4 \cdot 3)$ \\
\hline
\end{tabular}

* Localities of Prilep and Bitolj (southern Yugoslavia) and Novi Sad and Zagreb (northern Yugoslavia).

$\dagger$ No. of children investigated for the presence of bacteria/viruses.

$P$ values: $\ddagger P<0.05 ; \S P<0.005 ; \| P<0.001$

Table 2. Distribution of enteropathogens in different age groups of children with diarrhoea $(D)$ and of healthy controls $(C)$ in Yugoslavia (August-November 1986)

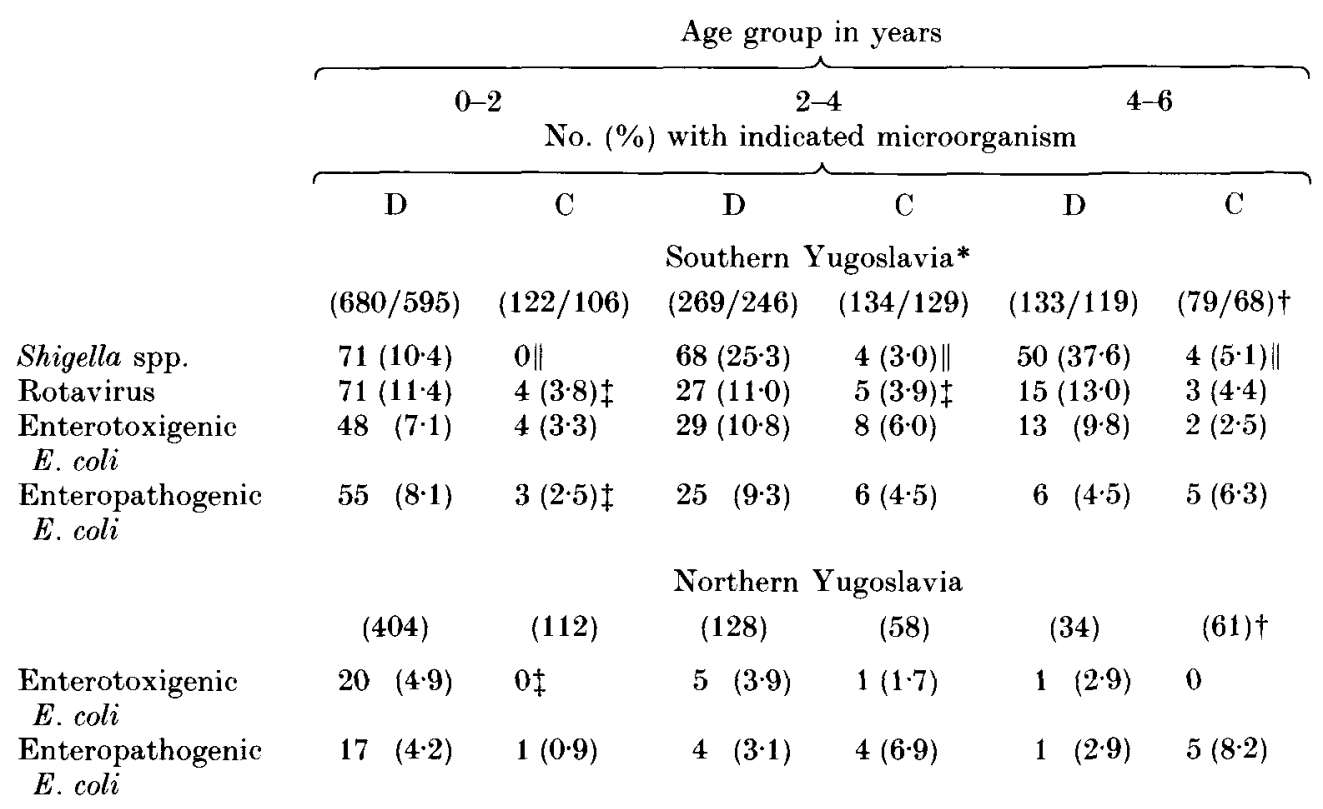

* See Table 1 for explanations. 
Table 3. Detection rates of entertoxigenic Escherichia coli in children with diarrhoea $(D)$ and in healthy controls $(C)$ in relation to enterotoxin production and to expression of mannose-resistant hemagglutination

\begin{tabular}{lcccc} 
& \multicolumn{4}{c}{ No. $(\%)$ of positive cases } \\
& $\begin{array}{c}\text { Southern Yugoslavia } \\
\text { D }\end{array}$ & $\mathrm{C}$ & Northern Yugoslavia \\
& $(1082)$ & $(335)$ & $\mathrm{D}$ & $\mathrm{C}$ \\
ETEC/LT* & $35(3 \cdot 2)$ & $5(1 \cdot 5)$ & $(566)$ & $(231)$ \\
ETEC/ST & $32(3 \cdot 0)$ & $4(1 \cdot 2)$ & $7(1 \cdot 2)$ & $1(0 \cdot 4)$ \\
ETEC/LT/ST & $47(4 \cdot 3)$ & $5(1 \cdot 5)$ & $3(0 \cdot 5)$ & 0 \\
ETEC/MRHA+ & $52(4 \cdot 8)$ & $3(0 \cdot 9) \|$ & $4(0 \cdot 7)$ & 0 \\
ETEC/MRHA & $62(5 \cdot 7)$ & $11(3 \cdot 3)$ & $22(3 \cdot 9)$ & $1(0 \cdot 4) \S$
\end{tabular}

* Enterotoxigenic E. coli (ETEC) which produced heat-labile (LT). heat-stable (ST) enterotoxin, or both (LT/ST), and which exhibited or not mannose-resistant hemagglutination (MRHA + and MRHA - respectively) of human group A and/or bovine erythrocytes.

$P$ values: $¥ P<0.02 ; \S P<0.005 ; \| P<0.001$.

up to the age of 4 years in comparison to healthy controls in southern Yugoslavia, and in the 0-2 year age group in the northern part. In the oldest children in both parts of Yugoslavia, and in children aged 2-4 years in the northern part, these agents were more commonly found in healthy controls. In southern Yugoslavia shigellae showed a continuous increase with age, whereas rotavirus was found with similar frequencies in all age groups.

Of the ETEC isolated in southern Yugoslavia, $52(40 \cdot 6 \%)$ produced both LT and ST, $36(28 \cdot 1 \%)$ strains elaborated ST only, and $40(31.3 \%)$ strains were L'Tpositive only. In the northern part, $3(11 \cdot 1 \%)$ strains produced both enterotoxins, $16(59 \cdot 3 \%)$ strains elaborated ST, and $8(29 \cdot 6 \%)$ produced LT. Fifty-five $(43 \%)$ out of 128 ETEC strains, isolated in southern part of Yugoslavia, exhibited MRHA of human and/or bovine erythrocytes in comparison to only $4(\mathbf{1 4} \cdot 8 \%)$ of 27 strains isolated in northern Yugoslavia. MRHA was expressed by $43(78 \cdot 2 \%)$ of 55 ETEC/LT/ST, $15(28.8 \%)$ of 52 ETEC/ST, and by $1(2 \cdot 1 \%)$ of 48 ETEC/LT. All strains producing one or both enterotoxins, as well as strains exhibiting or not MRHA, were more commonly isolated from stools of children with diarrhoea in both parts of Yugoslavia (Table 3).

Serogroups more frequently encountered among EPEC were: O 111, O 119, O 128, O 127, O 55, O 142, and O 44 (Table 4). Of 109 EPEC strains, isolated from ill children in both parts of Yugoslavia, $19(17 \cdot 4 \%)$ exhibited localized adherence (LA) to HEp-2 tissue culture cells, and $3(2 \cdot 7 \%)$ displayed diffuse adherence (DA). Of 24 strains, isolated from well children, only one exhibited DA. Strains expressing LA belonged to serogroups O 119 (12 strains), O 142 (6 strains), and O 111 (1 strain), whereas the strains with DA were of serogroup O 114 (3 strains) and $O 86$ (1 strain).

With the available antisera for $E$. coli $(\mathrm{O} 1, \mathrm{O} 2, \mathrm{O} 4, \mathrm{O} 6, \mathrm{O} 25, \mathrm{O} 75$, and $\mathrm{O} 78$, in addition to antisera for classical EPEC, listed in materials and methods), we were able to determine the serogroup of only $20(12.9 \%)$ of 155 isolated ETEC 
Table 4. Serogroups of enteropathogenic Escherichia coli strains isolated in children with diarrohea $(D)$ and in healthy controls $(C)$

\begin{tabular}{|c|c|c|c|c|c|}
\hline \multirow[b]{3}{*}{ Serogroup } & \multicolumn{5}{|c|}{ No. of strains with indicated serogroup } \\
\hline & \multicolumn{2}{|c|}{ Southern Yugoslavia } & \multicolumn{2}{|c|}{ Northern Yugoslavia } & \multirow[b]{2}{*}{ Total } \\
\hline & $\begin{array}{c}\mathrm{D} \\
(n=1082)\end{array}$ & $\begin{array}{c}\mathrm{C} \\
(n=335)\end{array}$ & $\begin{array}{c}\mathrm{D} \\
(n=566)\end{array}$ & $\begin{array}{c}\mathrm{C} \\
(n=231)\end{array}$ & \\
\hline O 18 & 4 & 0 & 0 & 0 & 4 \\
\hline 044 & 10 & 0 & 3 & 2 & 15 \\
\hline 055 & 7 & 0 & 4 & 0 & 11 \\
\hline O 86 & $4(1 \mathrm{DA}) *$ & 1 & 1 & 1 & 7 (1DA) \\
\hline O 111 & 16 & 0 & $3(1 \mathrm{LA})$ & 1 & 20 (1LA) \\
\hline 0112 & 1 & 0 & 2 & 0 & 3 \\
\hline O 114 & $5(2 \mathrm{DA})$ & $1(1 \mathrm{DA})$ & 0 & 0 & $6(3 \mathrm{DA})$ \\
\hline O 119 & 15 (10LA) & 2 & $2(2 \mathrm{LA})$ & 0 & 19 (12LA) \\
\hline O 125 & 3 & 1 & 1 & 0 & 5 \\
\hline O 126 & 2 & 3 & 1 & 1 & 7 \\
\hline O 127 & 5 & 1 & 4 & 2 & 12 \\
\hline O 128 & 4 & 5 & 1 & 3 & 13 \\
\hline O 142 & 11 (6LA) & 0 & 0 & 0 & 11 (6LA) \\
\hline Total & 87 & 14 & 22 & 10 & 133 \\
\hline
\end{tabular}

* Number in parenthesis indicates number of strains which expressed diffuse or localized adherence to HEp-2 cells (DA and LA, respectively).

Table 5. Mixed infections in children with acute diarrhoea in southern Yugoslavia

$\begin{array}{lcc} & \text { Enterotoxigenic } & \text { Enteropathogenic } \\ \text { Enteropathogen } & E . \text { coli }(n=32) & E . \text { coli }(n=29) \\ \text { Shigella spp. } & 15 & 9 \\ \text { Rotavirus } & 10 & 14^{*} \\ \text { Enterotoxigenic } & 0 & 6 \\ \text { E. coli } & & 2^{*} \\ \text { Enteropathogenic } & 6 & 0 \\ \text { E. coli } & 1 & \end{array}$

* One patient had a triple infection with two different serogroups of enteropathogenic $E$. coli and rotavirus; other dual infections were: one shigella and $C$.jejuni and one shigella and viruslike particles.

strains. Nine belonged to serogroup $O 128,4$ to $O 78$, and one each to $\mathrm{O} 119,0142$, $\mathrm{O} 25, \mathrm{O} 125, \mathrm{O} 127, \mathrm{O} 4$ and $\mathrm{O} 6$ serogroups.

Multiple infections were encountered in 32 of the ETEC and 29 of the EPEC infections most commonly with shigellae and rotavirus (Table 5). Only one patient had a triple infection with two EPEC strains of different serogroup and rotavirus. Of two controls, which were doubly infected, one harboured ETEC and rotavirus, and the other ETEC and EPEC.

\section{DISCUSSION}

Although ETEC were discovered two decades ago, no extensive study on their importance in sporadic diarrhoea in the Balkan region has yet been carried out. 
Our study revealed that these agents are associated with diarrhoeal disease of childhood in the investigated localities of Yugoslavia. The rates of isolation varied. In the southern part, where the population's economic potential is comparatively lower, the percentage of ETEC isolations in ill children exceeded $10 \%$, similar to the results obtained in Zaire (De Mol et al. 1983), and Ethiopia (Stintzing et al. 1981); in the northern part, with a higher socio-economic background, they were detected in less than $5 \%$ of children with diarrhoea. These results reflect the findings obtained throughout the world: in developed regions ETEC are unimportant in the aetiology of acute diarrhoea, whereas in developing countries they are one of the leading causes of this disease (Gross \& Rowe, 1985). The influence of sanitation and socio-economic status rather than geographic location on the incidence of ETEC-diarrhoea is well documented in the USA, where it is commonly encountered on Indian reservations (Hughes et al. 1980), but is rare in urban populations (Kapikian et al. 1976). Our isolation rate of ETEC was higher in ill children aged 2-4 years as was found in Thailand (Echeverria et al. 1985). These agents show decreased prevalence with age in almost all parts of the world except Bangladesh, where they are a more important cause of diarrhoea in adults than in children (Black et al. 1980).

In relation to enterotoxin production, strains from southern Yugoslavia were predominantly ETEC/LT/ST, and from the northern part ETEC/ST. Strains producing ST only were most commonly found in the investigations in Bangladesh (Black et al. 1980), and Brazil (Guerrant et al. 1983), whereas ETEC/LT dominated in Mexico (Donta et al. 1977), Canada (Brunton et al. 1980), and Ethiopia (Stintzing et al. 1981). MRHA was found most frequently among our ETEC/LT/ST, indicating the presence of colonization factor antigens (CFA-I, CFA-II, PCF 8775) on these strains. It has been suggested that ETEC strains elaborating LT only, as well as strains without CFAs, are not capable of causing diarrhoea, since they were found with similar or even higher rates in controls (Hughes et al. 1980; Spencer et al. 1980). In our study both ETEC/LT and the strains which did not cause MRHA were more commonly found in ill children (Table 3). Of serogroups which we were able to determine, $\mathrm{O} 128$ and 078 were the most frequently encountered among ETEC. It was recognized in this study that toxigenic strains sometimes share somatic antigens with classical EPEC as had been shown by Brunton et al. (1980).

There has been much debate about the role of EPEC in acute diarrhoea, especially in relation to diagnostic methods used for their detection. By determination of serogroup we found these agents more commonly in ill children up to 4 years of age in southern Yugoslavia, while in northern part of the country they were more frequently isolated from stools of children with diarrhoea only in the $0-2$ year age group. The reason(s) for this discrepancy is unknown, but it seems that routine serogrouping is not a reliable method for the diagnosis of diarrhoea caused by EPEC; the determination of serotype ( $O$ and $\mathrm{H}$ antigen) may be a more accurate method (Robins-Browne, 1987).

Recently it has been found that potentially diarrhoeagenic $E$. coli, including EPEC, expressed adherence to cultured cell lines (HEp-2, HeLa) in two different manners: LA and DA (Scaletsky, Silva \& Trabulsi, 1984). LA is predominantly encountered among EPEC, and DA among non-EPEC E. coli (Mathewson et al. 
1987). In the present study, all EPEC exhibiting LA were isolated from ill children $(P<0 \cdot 02)$. The association of strains expressing LA with diarrhoea was also found by Karch, Heesemann \& Laufs (1987), and Mathewson el al. (1987). Therefore, it seems that LA is a virulence marker of of EPEC. Nataro et al. (1985b) and Levine (1987) proposed classification of EPEC strains in two groups: class I (serogroups O 55, O 86, O 111, O 119, O 125, O 126, O 127, O 128ab, and O 142), which usually express LA and possess a plasmid coding for this type of adherence (EAF plasmid), and class II (serogroups O 44, O 112, and O 114), which neither exhibit LA nor possess EAF plasmid. In this study, LA was restricted to only a few serogroups (O 111, O 119 and $O$ 142) similar to the findings of others (Karch, Heesemann \& Laufs, 1987; Mathewson et al. 1987; Echeverria et al. 1987); all of our strains exhibiting LA were of proposed class $I$.

On the other hand, the pathogenicity of $E$. coli displaying DA was not clear in a volunteer study (Mathewson et al. 1986). Furthermore, Mathewson et al. (1987) found the association of these strains with acute diarrhoea in Mexican children, but this was not confirmed in the study in Thailand (Chatkaeomorakot et al. 1987). Nataro et al. (1987) described three distinctive patterns of adherence: LA, DA (true diffuse adherence), and aggregative adherence, of which only strains expressing LA and aggregative adherence were associated with diarrhoea in Chilean children. We found diffusely adherent $E$. coli with similar frequencies in children with and without diarrhoea. Interestingly, all of our strains exhibiting DA also exhibited MRHA of human group A erythrocytes (manuscript in preparation).

In the southern part of Yugoslavia shigellae were the leading causes of childhood diarrhoea during the investigation period, rotavirus ranked the second, whereas salmonellae and $Y$. enterocolitica were numerically unimportant agents of sporadic diarrhoea. The ratio of bacterial vs. viral infections was $2.5: 1$, as is characteristic for regions with endemic diarrhoea with a relatively high morbidity rate. In developed parts of the world viruses usually predominate, the ratio being 1:4-6 (Koopman et al. 1984). Almost 16\% of our controls yielded potential enteropathogen, in line with the results obtained in area with poor sanitation (Leksomboon et al. 1984).

In conclusion, our study revealed that ETEC were associated with acute diarrhoea in preschool children in Yugoslavia, whereas the association of EPEC with this illness, as determined by serogrouping, was documented only in children up to two years of age. During the seasonal peak of enteric diseases bacteria were dominant cause of childhood diarrhoea in southern part of Yugoslavia with shigellae being the most frequent agents.

\section{REFERENCES}

Black, R. E., Merson, M. H., Rahman, M. M., Yunus, M., Alim, A., Huq, I., Yolken, R. H. \& Curlin, G. T. (1980). Two-year study of bacterial, viral, and parasitic agents associated with diarrhea in rural Bangladesh. Journal of Infectious Diseases 142, 660-664.

Brunton, J., Hinde, D., Langston, C., Gross, R., Rowe, B. \& Gurwith, M. (1980). Enterotoxigenic Escherichia coli in Central Canada. Journal of Clinical Microbiology 11. $343-348$. 
Chatkafomorakot, A., Echeverria, P., Taylor, D. N., Bettelheim, K. A., Bi.acklow, N. R., Sethabutr, O., Seriwatana, J. \& KaPer, J. (1987). HeLa cell-adherent Escherichia coli in children with diarrhea in Thailand. Journal of Infectious Diseases 156, 669 672.

Dean, A. G., Chisg, Y. C., Williams, R. G. \& Harden, L. B. (1972). Test for Escherichia coli enterotoxin using infant mice: application in a study of diarrhea in children in Honolulu. Journal of Infectious Diseases 125, 407-410.

De Mol, P., Brasseur, D., Hemelhof, W., Kalala, T., Butzler, J. P. \& Vis, H. L. (1983) Enteropathogenic agents in children with diarrhoea in rural Zaire. Lancet i, 516-518.

Donta, S. T., Wallace, R. B., Whipp, S. C. \& Olarte, J. (1977). Enterotoxigenic Escherichia coli and diarrheal disease in Mexican children. Journal of Infectious Diseases 135, 482-485.

Echeverria, P., Seriwatana, J., Taylor, D. N., Yanggratoke, S. \& Tirapat, C. (1985). A comparative study of enterotoxigenic Escherichia coli, Shigella, Aeromonas, and Vibrio as etiologies of diarrhea in northeastern Thailand. American Journal of Tropical Medicine and Hygiene 34, 547-554.

Echeverria, P., Taylor, D. N., Donohue-Rolfe, A., Supawat, K., Ratchtrachenchai, O. KaPer, J. \& Keusch, G. T. (1987). HeLa cell adherence and cytotoxin production by enteropathogenic Escherichia coli isolated from infants with diarrhea in Thailand. Journal of Clinical Microbiology 25, 1519-1523.

Edwards, P. R. \& Ewing, W. H. (1972). Identification of Enterobacteriaceae, 3rd edn. Burgess Publishing Company.

Evass, D. J., Evans, D. G. \& DuPont, H. L. (1979). Hemagglutination patterns of enterotoxigenic and enteropathogenic Escherichia coli determined with human, bovine, chicken, and guinea-pig erythrocytes in the presence and absence of mannose. Infection and Immunity 23, 336-346.

Gross, R. J. \& Rowe, B. (1985). Escherichia coli diarrhoea. Journal of Hygiene 95, 531-550.

Guerrant, R. L., Brunton, L. L., Schaitman, T. C., Rebhun, L. I. \& Gilman, A. G. (1974). Cyclic adenosine monophosphate and alteration of chinese hamster ovary cell morphology: a rapid, sensitive in vitro assay for the enterotoxins of Vibrio cholerae and Escherichia coli. Infection and Immunity 10, 320-327.

Guerrant, R. L., Kirchioff, L. V., Shields, D. S., Nations, M. K., Leslie, J., Sousa, M. A., Aracjo, J. G., Correia, L. L., Saver, K. T., McClelland, K. E., Trowbridge, F. L. \& Hughes, J. M. (1983). Prospective study of diarrheal illnesses in Northeastern Brazil patterns of disease, nutritional impact, etiologies, and risk factors. Journal of Infectious Diseases 148, 986-997.

Hughes, J. M., Rouse, J. D., Barada, F. A. \& Guerrant, R. L. (1980). Etiology of summer diarrhea among the Navajo. American Journal of Tropical Medicine and Hygiene 29, 613-619.

Kapikian. A. Z., Kim, H. W., Wyatt, R. G., Lee Cline, W., Arrobio, J. O., Brandt, C. D. Rodrigcez, W. J., Sack, D. A., Chanock, R. M. \& Parrot, R. H. (1976). Human reoviruslike agent as the major pathogen associated with 'winter' gastroenteritis in hospitalized infants and young children. New England Journal of Medicine 294, 965-972.

Karch, H., Heesemann, J. \& Laufs, R. (1987). Phage associated cytotoxin production by and enteroadhesiveness of enteropathogenic Escherichia coli isolated from infants with diarrhea in West Germany. Journal of Infectious Diseases 155, 708-715

Konowalchlk, J., Speirs, J. I. \& Stavric, S. (1977). Vero response to a cytotoxin of Escherichia coli. Infection and Immunity 18, 775-779.

Koopman, J. S., Turkish, V. J., Monto, A. S., Gouvea, V., Srivastava, S. \& Isaacson, R. E. (1984). Patterns and etiology of diarrhea in three clinical settings. American Journal of Epidemiology 119, 114-123.

Leksomboon, U., Fcheverria, P., Scvongse, C. \& Duangmani, C. (1981). Viruses and bacteria in pediatric diarrhea in Thailand : a study of multiple antibiotic-resistant enteric pathogens. American Journal of Tropical Medicine and Hygiene 30, 1281-1290.

Levine, M. M. (1987). Escherichia coli that cause diarrhea: enterotoxigenic, enteropathogenic, enteroinvasive, enterohemorrhagic, and enteroadherent. Journal of Infectious Diseases 155 $377-389$.

Mathewson, J. J., Johnson, P. C., DuPont, H. L., Satterwite, T. K. \& Winsor, D. K. (1986). Pathogenicity of enteroadherent Escherichia coli in adult volunteers. Journal of Infectious Diseases 154, 524-527. 
Mathewson, J. J., Oberhelman, R. A., DuPont, H. L., Cabada, F. J. \& Garibay, E. V. (1987). Enteroadherent Escherichia coli as a cause of diarrhea among children in Mexico. Journal of Clinical Microbiology 25, 1917-1919.

Nataro, J. P., Scaletsky, I. C. A., Kaper, J. B., Levine, M. M. \& Trabulsi, L. R. (1985a). Plasmid-mediated factors conferring diffuse and localized adherence of entaropathogenic Escherichia coli. Infection and Immunity 48, 378-383.

Nataro, J. P., Baldini, M. M., Kaper, J. B., Black, R. E., Bravo, N. \& Levine, M. M. $(1985 b)$. Detection of an adherence factor of enteropathogenic Escherichia coli with a DNA probe. Journal of Infectious Diseases 152, 560-565.

Nataro, J. P., Kaper, J. B., Robins-Browne, R., Prado, V., Vial, P. \& Levine, M. M. (1987). Patterns of adherence of diarrheagenic Escherichia coli to HEp-2 cells. Pediatric Infectious Diseases Journal 6, 829-831.

Robins-Browne, R. M. (1987). Traditional enteropathogenic Escherichia coli of infantile diarrhea. Journal of Infectious Diseases 9, $28-53$.

Scaletsky, I. C. A., Silva, M. L. M. \& Trabulsi, L. R. (1984). Distinctive patterns of adherence of enteropathogenic Escherichia coli to HeLa cells. Infection and Immunity 45 , 534-536.

Spencer, H. C., Wells, J. G., Gary, W. G., Sondy, J., Puhr, N. D. \& Feldman, R. A. (1980). Diarrhea in a non-hospitalized rural Salvadoran population: the role of enterotoxigenic Escherichia coli and rotaviruses. American Journal of Tropical Medicine and Hygiene 29. 246-253.

Stintzing, G., Bäck, E., Tufveson, B., Johnson, T., Wadström, T. \& Habte, D. (1981). Seasonal fluctuations in the occurrence of enterotoxigenic bacteria and rotavirus in paediatric diarrhoea in Addis Ababa. Bulletin of the World Health Organization 59, 67-73.

WHO, Geneva (1983). Weekly Epidemiological Report 58, 241.

WHO, Copenhagen (1981). Surveillance and control of acute diarrhoeal diseases. Report on a WHO meeting. Rome, 8-11 April 1980. EURO Reports and Studies 44, pp. $2-8$. 